\title{
Impedance cardiography: recent applications and developments.
}

\author{
Sofienne Mansouri $^{1 *}$, Tareq Alhadidi ${ }^{1}$, Souhir Chabchoub ${ }^{2}$, Ridha Ben Salah ${ }^{2}$ \\ ${ }^{1}$ Department of Medical Equipment Technology, College of Applied Medical Sciences, Prince Sattam Bin Abdulaziz \\ University, Al-Kharj, Kingdome of Saudi Arabia \\ ${ }^{2}$ University of Tunis El-Manar, ISTMT, Laboratory of Biophysics and Medical Technologies, Tunisia
}

\begin{abstract}
The main purpose of this paper is to highlight the main aspects of impedance cardiography ICG method and to review the recent advances and developments in this research area. Precisely, the validation and the clinical applications of ICG are carefully demonstrated in this review. Particularly, in the validation and the recent advances in ICG, only the papers published during the last five years (from 2013 until 2017) have been undertaken.
\end{abstract}

Keywords: Impedance cardiography, Assessment, Hemodynamic parameters, Non-invasive.

Accepted on January 23, 2018

\section{Introduction}

Cardiac Output (CO) is an interesting hemodynamic parameter which is used generally to evaluate the mechanical activity of the heart. It can be used to guide therapeutic decisions-making in critically ill patients and for patients undergoing high-risk surgery [1]. Mathematically, $\mathrm{CO}$ is equal to the product of heart rate (HR) and Stroke Volume (SV); it is expressed in L/ min. Clinically, CO could be useful in the assessment of cardiovascular disease, especially patients with coronary artery disease [2] and patients with congestive heart failure [3]. However, the accurate measurement of this parameter is usually based on invasive methods such as thermodilution Pulmonary Artery Catheter (PAC) which was considered as the clinical reference standard "gold standard" for assessing hemodynamic parameters [4-6]. These invasive methods are dangerous, can increase mortality in critically ill patients, complicated, and require qualified and trained staff. To avoid these major limitations, minimally or non-invasive techniques are potentially needed. Despite the non-invasiveness of the Doppler echocardiography and the Magnetic Resonance Imaging (MRI), these techniques still expensive, complicated, and require highly skilled medical personnel. Furthermore, these non-invasive techniques are discontinuous and could not be used for real-time monitoring. To avoid all these disadvantages, Impedance Cardiography (ICG) technique has been introduced. ICG is a non-invasive, cost-effective, continuous, and simple tool of assessing hemodynamic parameters like SV and CO. It has a fast response time and it could be used as an ambulatory monitoring technique. Moreover, this technique can be easily practiced by nurses [7]. Therefore ICG technique is the main topic of this present review paper. Note that due to the rapid technological developments, the current review is limited to the papers that were published during the last 5 years (from 2013 until 2017). For further information about the articles published before 2013, the reader can refer to $[8,9]$.

\section{Fundamental Basis of Impedance Cardiography}

\section{Impedance cardiography measurements}

Impedance cardiography is a non-invasive tool of monitoring electrical impedance changes in the thorax [10]. It is considered as a diagnostic technique for measuring the electrical properties of biological tissues in the thorax [8]. The principle of this technique consists of applying a constant, alternating, high frequency and small current (frequency range between 20 and $100 \mathrm{KHz}$ and the current amplitude between 1 and $5 \mathrm{~mA}$ ) through two outer electrodes and then acquiring the electrical voltage difference by using two inner electrodes. Several electrode configurations have been proposed in the literature [11]; the most popular ones are described as follows. Tetrapolar-band electrode configuration has been developed to record the thoracic impedance changes during the cardiac cycle. In this configuration two electrodes are placed around the neck and two other electrodes around the upper abdomen. Furthermore, the injected current was about $4 \mathrm{~mA}$ at $100 \mathrm{KHz}$ $[12,13]$. The tetrapolar-band electrode configuration is shown in Figure 1a, where E1 and E4 are the outer-band electrodes, whereas E2 and E3 are the inner-band electrodes which are placed around the base of the neck and the level of Xiphisternal, respectively. In [14], the four-band electrodes have been replaced by four-spot electrodes in order to ameliorate and facilitate measurements. Another electrode configuration has been described in [15-17] as shown in Figure $1 \mathrm{~b}$. It consists in injecting a current of $1 \mathrm{~mA}$ at $30 \mathrm{KHz}$ through two outer electrodes (electrodes E1 and E4) that are placed into 
the forehead and above the leading edge of the heart; the electrical voltage difference is measured by two inner electrodes (electrodes E2 and E3) which are placed between the outer electrodes, precisely on the left side of the patients' chest.

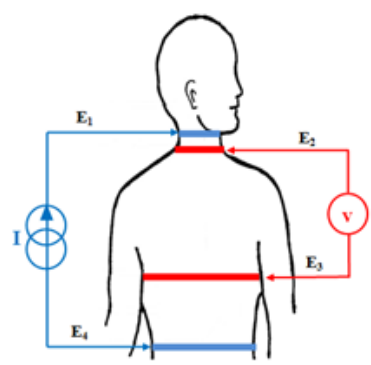

(a)

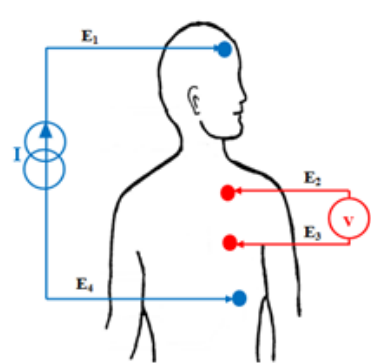

(b)
Figure 1. Electrode configurations for the impedance cardiography ICG signal measurements: (a) tetrapolar-band electrodes, (b) tetrapolar-spot electrodes.

\section{Impedance cardiography recording}

The acquired voltage is proportional to the impedance variation $(\Delta \mathrm{Z})$ of the explored thoracic region. Mathematically, the impedance $(Z)$ is defined by Ohm's law as the ratio between the measured electrical Voltage $(V)$ and the injected current signal (I). As the current strength is known, $\mathrm{Z}$ can be easily calculated. Impedance cardiography recording, denoted as $\mathrm{dZ} / \mathrm{dt}$, is the first derivative of the impedance variation signal $(\Delta \mathrm{Z})$. The typical ICG recording and its main characteristic points are shown in Figure 2. A, B, C, X and $\mathrm{O}$ are the main characteristic points which are related to distinct physiological events in the cardiac cycle. The point A presents the beginning of electromechanical systole and it is associated with the volume change occurring due to the active atrial contraction [18]. B is an important point which is used to calculate the SV and $\mathrm{CO}$; it denotes the beginning of the ejection time and it appears simultaneously with the opening of the aortic valve [19]. Numerous methods have been proposed in the literature to identify the true location of the B-point [20]. However, it has been reported that the marker of this point is not always apparent and it may occur at any point on the ascending portion of the trace before the $(d Z / d t)_{\max }$. Therefore, the precise identification of this point is paramount to ensuring accurate computation of $\mathrm{SV}$ and $\mathrm{CO}$ [21-23]. The point $\mathrm{C}$, noted also $(d Z / d t)_{\max }$, is taken at the peak of the ICG trace and it corresponds to the ventricular contraction. $\mathrm{X}$ is the lowest point after the peak $\mathrm{C}$; it is synchronized with the closure of the aortic valve and it indicates the end of the systole phase. The point $\mathrm{O}$ is associated with the changing of the volume during the diastolic phase of the cycle and the maximal opening of the mitral valve [24].

There are different characteristic time intervals which can be measured from simultaneous recordings of ICG and ECG traces. The Pre-Ejection Period (PEP) and the Left Ventricular Ejection Time (LVET), called also Ejection Time (ET), are the commonly used Systolic Time Intervals (STI); they are associated with the electromechanical systole of the left ventricle [25]. The PEP is the time interval between the $Q$ wave in the ECG trace and the B point in the ICG trace; it reflects an isovolumetric contraction phase of systole. The LVET is the time interval measured from the $\mathrm{B}$ point to the $\mathrm{X}$ point; it represents mechanical systole and it can be used to estimate the SV and the CO [26]. Another interval, referred as Initial Systolic Time Interval (ISTI), can be measured as the time period between the R peak in the ECG trace and the $\mathrm{C}$ point in the ICG trace. It has been emphasized that the end point of this interval (C-point) occurred around the same moment of the maximum diameter of the aortic arch [27]. Hence, ISTI can reflect the measure for the time delay between the electrical and mechanical pumping activity of the heart $[28,29]$.

Several signal processing algorithms have been proposed in order to accurately and easily detect the main characteristic points on the ICG traces [30-35]. Hence, the correct identification of these points may improve the determination of the time intervals as well as the assessment of hemodynamic parameters.
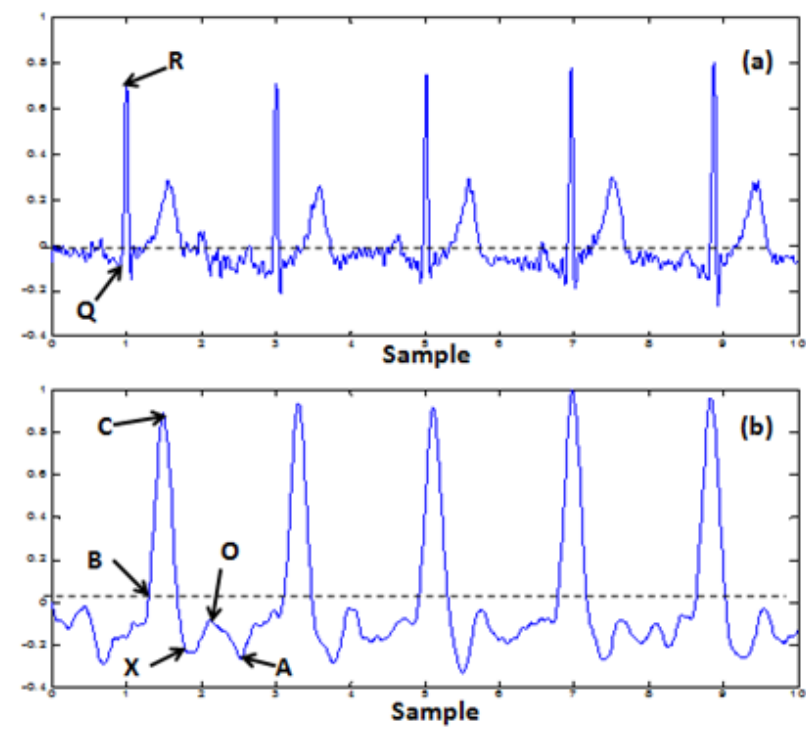

Figure 2. (a) ECG tracing, (b) Characteristic points in the impedance cardiography ICG tracing.

\section{The hemodynamic parameters}

Several hemodynamic parameters and indices can be estimated from the ICG recording [36]; these parameters can be described as follows:

The Heart Rate (HR), expressed in bpm.

The Stroke Volume (SV), expressed in $\mathrm{ml}$, is the volume of blood pumped by the left ventricle during one contraction cycle. The calculation of this important parameter will be discussed in the next sub-section.

The Stroke Index (SI), expressed in $\mathrm{ml} / \mathrm{m}^{2}$, is the ratio of the $\mathrm{SV}$ to the body surface area BSA (SV/BSA). 
The Cardiac Output (CO), expressed in L/min, is the volume of blood ejected by the heart into the systemic circulation during 1 min [19]. When the HR and the SV are known, CO can be easily computed $(\mathrm{CO}=\mathrm{HR} \times \mathrm{SV})$.

The Cardiac Index (CI), expressed in $\mathrm{L} / \mathrm{min} / \mathrm{m}^{2}$, is the ratio of the $\mathrm{CO}$ to the BSA (CO/BSA).

The Systemic Vascular Resistance (SVR), expressed in dyne.s. $\mathrm{cm}^{-5}$, is directly related to the Mean Arterial Pressure (MAP), the Central Venous Pressure (CVP) and the CO by the following equation: $\mathrm{SVR}=((\mathrm{MAP}-\mathrm{CVP}) / \mathrm{CO}) \times 80$.

The Systemic Vascular Resistance Index (SVRI), expressed in dyne. $. \mathrm{cm}^{-5} / \mathrm{m}^{2}$, is the ratio of the SVR to the BSA (SVR/ BSA).

The Systolic Time Ratio (STR) is the ratio of the pre-ejection period to the left ventricular ejection time (PEP/LVET); it is inversely proportional to the left ventricular function.

The Systolic Time Ratio Index (STRI), expressed in $\mathrm{s}^{-1}$, is the ratio of the STR to the time interval between two consecutive $\mathrm{R}$ waves in the ECG trace (STR/RR).

The thoracic fluid content (TFC), expressed in $K \Omega^{-1}$, is the inverse of the basic impedance $Z_{0}$ and it represents the total fluid volume in the chest. High impedance corresponds to less thoracic volume and hence low thoracic fluid content, but low impedance corresponds to more thoracic volume and hence high thoracic fluid content [26].

Velocity Index (VI), expressed in $/ 1000 / \mathrm{s}$, represents the maximum rate of impedance change and it is related to changes in aortic blood velocity.

Acceleration index (ACI), expressed in $/ 100 / \mathrm{s}^{2}$, represents the maximum rate of change of blood velocity and it is related to changes in aortic blood acceleration.

The Left Stroke Work Index (LSWI), expressed in $\mathrm{g} / \mathrm{m}^{2}$, is related to the MAP, the Pulmonary Capillary Wedge Pressure (PCWP) and the SI; it is defined by the following equation: $\mathrm{LSWI}=($ MAP-PCWP $) \times \mathrm{SI} \times 0.0136$.

The Left Cardiac Work Index (LCWI), expressed in $\mathrm{kg} . \mathrm{m} / \mathrm{m}^{2}$, is related to the MAP, the PCWP and the CI; it is defined by the following equation: LSWI= (MAP-PCWP $) \times \mathrm{SI} \times 0.0144$.

The Heather Index (HI) is a unique index of myocardial contractility. It is defined as the ratio of the $\mathrm{C}$ point amplitude $(d Z / d t)_{\max }$ to the Q-C time interval (Q wave in the ECG trace and $\mathrm{C}$ point in the ICG trace); it is expressed in $\Omega / \mathrm{s}^{2}$ [22].

\section{The stroke volume calculation}

Several equations for stroke volume calculation based on the ICG recording have been developed in the literature. In this sub-section the most used equations will be presented. Please note that for more details or demonstration about each cited formula, the reader can refer to [37].

Kubicek et al. [12] assumed that the adult thorax acts as a cylinder. Thus, the Kubicek equation is expressed as follows:
$S V=\rho \cdot \frac{L_{0}^{2}}{z_{0}^{2}} \cdot\left(\frac{d Z}{d t}\right)_{\max } \cdot L V E T \rightarrow(1)$

Where SV is the stroke volume $\left(\mathrm{cm}^{3}\right.$ or $\left.\mathrm{ml}\right) ; \rho$ is the resistivity of the blood $(\Omega . \mathrm{cm})$ which is considered constant during the cardiac cycle $(\rho=150 \Omega . \mathrm{cm}) ; L_{0}$ is the distance between the inner electrodes $(\mathrm{cm}) ; Z_{0}$ is the basic impedance measure between the inner electrodes $(\Omega) ;(d Z / d t)_{\max }$ is maximum value of the ICG waveform $(\Omega / s)$; LVET is the left ventricular ejection time $(s)$.

Stramek et al. [38] proposed another thorax model; they assumed that the adult thorax acts as a truncated cone and they eliminated the blood resistivity term from the equation ( $\rho$ is not considered). The Stramek equation is presented as follows:

$S V=\frac{L_{0}^{3}}{4.25 \times Z_{0}} \cdot\left(\frac{d Z}{d t}\right)_{\max } . L V E T \rightarrow(2)$

As mentioned above $L_{0}$ is the distance between the inner electrodes $(\mathrm{cm})$; it is equal to $17 \%$ of the subject height $H(\mathrm{~cm})$ $(L O=0.17 \times \mathrm{H})$.

Bernstein et al. [39] modified the Stramek equation by introducing a new term that is related to the ideal body weight. Therefore, the Stramek-Bernstein equation is given below:

$S V=\delta \cdot \frac{(0.17 \times H)^{3}}{4.25 \times Z_{0}} \cdot\left(\frac{d Z}{d t}\right)_{\max } \cdot \operatorname{LVET} \rightarrow(3)$

In this equation a correction factor $\delta$ is introduced; this factor is a dimensionless parameter which is related to the ideal body weight W (kg).

Bernstein et al. [40] added other modifications to the StramekBernstein formula; the Bernstein equation is presented as follows:

$S V=\frac{V_{\text {ITBV }}}{\varepsilon^{2}} \cdot \sqrt{\frac{\left(\frac{d Z}{d t}\right)_{\max }}{Z_{0}}} \cdot$ LVET $\rightarrow$ (4)

Where VITBV is the intra-thoracic blood volume and it is related to the body weight $\mathrm{W}(\mathrm{kg}), \mathrm{VITBV}=16 . \mathrm{W}^{1.02}(\mathrm{ml}) ; \varepsilon$ is a dimensionless index of transthoracic aberrant conduction (for all $Z_{0}<20 \Omega, 0<\varepsilon<1$ and for all $\left.Z_{0} \geq 20 \Omega, \varepsilon=1\right)$.

\section{Validity of Impedance Cardiography: Comparison with Other Methods}

In order to establish the accuracy and the reliability of ICG in the assessment of SV, CO and other hemodynamic parameters related to different cardiac cycle events, this technique has been widely compared to different invasive and non-invasive methods [41-44]. The validation of this technique has been performed on numerous clinical cases by using various ICG device marks. In fact, some studies demonstrated satisfactory agreement between ICG and a reference standard technique, while others proved the inaccuracy and the uselessness of ICG method. 
Noda et al. [45] compared ICG with echocardiography by measuring the quotient PEP/LVET in two different settings: optimized setting and right ventricle-only pacing. The authors showed, firstly, that the PEP/LVET values determined by ICG and echocardiography were positively correlated. Secondly, they demonstrated that the PEP/LVET values measured by ICG were decreased in the optimized setting compared with that in right ventricle-only pacing. Therefore, they affirmed that the PEP/LVET determined by ICG can be used as a positive marker for the optimization of Cardiac Resynchronization Therapy (CRT). Another study, published by Germain et al. [46], aimed to compare between ICG (NiCaS device) and Doppler echocardiography by measuring the $\mathrm{SV}$ in patients receiving maintenance Hemodialysis (HD) treatments. In this study, the SV is measured during the first and last hour of each HD treatment. They observed high correlations between ICGNiCas and echocardiography measurements during the first and the last hours of treatment. Therefore, they concluded that the ICG-NiCas could be used as a useful and reliable method for monitoring SV during HD.

McIntyre et al. [47] evaluated the agreement between ICG and echocardiography by assessing the SV and $\mathrm{CO}$ in healthy third trimester pregnant women. The authors found that the agreement between the two techniques was poor throughout the assessment; hence they concluded that the use of ICG for monitoring SV and $\mathrm{CO}$ is not endorsed in healthy women in late pregnancy. Burlingame et al. [48] compared ICG with echocardiography by measuring different hemodynamic parameters at three different time points and two different maternal positions during pregnancy. In this study, ICG and echocardiography gave significant correlations in some, but not all hemodynamic parameter measurements. In particular, they observed that the SV, the $\mathrm{CO}$ and the SVR parameters measured by ICG were significantly correlated with those measured by echocardiography when patients were in the left lateral recumbent supine position (LLRSP) in intrapartum period. Furthermore, they demonstrated that ICG could detect the small change in $\mathrm{SV}$ associated with maternal position change in the antepartum period.

Kaszuba et al. [49] tried to search an association between the ICG-derived parameters and the Ejection Fraction value (EF) determined by echocardiography in patients with chronic heart failure. After evaluating different ICG parameters, they found that only the PEP, the LVET and the STR are highly correlated with EF. In this study, the authors affirmed that ICG may be considered as an efficient technique for evaluating reduced left ventricular function.

Faini et al. [50] performed a comparison between cardiac index (CI) values determined by ICG (precisely the Hotman device) and those determined by thermodilution. In this study, all patients were subjected to open heart surgery. The authors noticed that the CI measured with ICG correlate highly with CI determined by thermodilution. Then, they demonstrated that the ICG-Hotman device may perform well as a moderately invasive tool in high risk cardiac patients. Kupersztych-Hagege et al. [51] used another ICG-derived technology, referred as bioreactance device (Nicom device). They compared CI values estimated by Nicom device with those provided by transpulmonary thermodilution $\left(\mathrm{PiCCO}_{2}\right.$ device) in response to passive leg raising and volume expansion in critically ill patients. They noticed that there was no significant correlation between the two methods after volume expansion. Therefore, they affirmed that bioreactance could not predict fluid responsiveness through the passive leg raising test in critically ill patients. In conclusion, they said that Nicom device is unable to provide an accurate estimation of CI values or relative changes in critical care patients.

Lorne et al. [52] tried to compare the $\mathrm{CO}$ values measured by ICG (Niccomo device, Medis) and by Oesophageal Doppler monitoring (ODM) in general surgery patients. They found that the $\mathrm{CO}$ values correlated significantly between the two methods. Also, they noticed that the LVET values measured by ICG correlated with those measured by ODM. Therefore, they concluded that the ICG is a useful method for monitoring $\mathrm{CO}$ in patients undergoing surgery.

Borzage et al. [53] attempted to evaluate the accuracy of ICG compared to phase-contrast magnetic resonance imaging (MRI) by measuring the SV at rest and during exercise in healthy subjects. The SV measurements showed that the agreement between ICG and MRI is poor; they signalled that ICG yielded an underestimate of SV at low values and an overestimate at high values. Consequently, they proved that ICG technique is not recommended for measuring SV when comparing it with MRI. Trinkmann et al. [54] tried to assess the accuracy and the reproducibility of a novel algorithm implemented in ICG device, known as Electrical Velocimetry (EV), compared to Cardiac Magnetic Resonance Imaging (CMRI) in numerous patients with different cardiac and pulmonary diseases. They proved that the EV showed a high reproducibility, but an insufficient agreement with CMRI.

The EV technology has been evaluated in the study of Blohm et al. [55]. The authors compared the SV values measured by EV with those measured by Transthoracic Echocardiography (TTE) in pediatric intensive care patients. They noted a statistically high significant correlation of SV measurements by EV and TTE. Then, they concluded that the EV is suitable for monitoring SV and hence CO in children. Grollmuss et al. [56] tried also to compare EV with sporadical TTE in other clinical application. In this work, the $\mathrm{CO}$ assessed by EV is compared to the $\mathrm{CO}$ assessed by TTE in low and very low birth weight infants with spontaneously and artificially ventilated. They found that there was clinically acceptable agreement between EV and TTE for CO measuring. They signalled that $\mathrm{EV}$ could be used as a valuable method for monitoring $\mathrm{CO}$ in premature new-borns.

The validation of ICG technique has been performed not only in human but also in animals. Sasaki et al. [57], in their study, compared between EV and pulmonary artery catheter thermodilution by measuring different hemodynamic parameters (CI, SV, SVI, SVRI) in dogs undergoing cardiovascular surgery. They studied also the relationship between SV variation (SVV) and SV as well as the relationship 
between Central Venous Pressure (CVP) and SV in order to predict fluid responsiveness. They found that the CI values measured by EV demonstrated an acceptable agreement with those measured by thermodilution; consequently, EV could accurately monitor CO. Moreover, unlike CVP, SVV determined by EV was considered as a reliable predictor of fluid responsiveness during mechanical ventilation in dogs.

\section{Clinical and Recent Applications of Impedance Cardiography}

ICG technique has been successfully used in several clinical applications. In this section, the most common clinical applications of ICG will be discussed.

\section{Hypertension}

Hypertension (high blood pressure) is considered as the most common risk-factor for premature cardiovascular disease. The early detection and the good management of hypertension can reduce the risk of further complications [58,59]. ICG technique is widely used in the diagnosis and the management of hypertension [60-66].

Barochiner et al. [67] investigated the ability of CI, SVRI, Blood Pressure (BP), and HR parameters derived from ICG method, to distinguish hypertensive patients with exaggerated orthostatic blood pressure variation (EOV). The measurements were performed in supine and standing positions in order to take account the effects of postural changes on hemodynamic parameters. Three groups of patients were defined in this study based on the BP variations: Normal orthostatic BP variation (NOV), orthostatic hypotension (OHypo), and orthostatic hypertension (OHyper). They noticed a very important raise in SVRI and HR in patients with OHyper compared to the other patients, precisely in standing position. Therefore, they concluded that patients belonging to the OHyper group presented distinct hemodynamic parameters.

Krzesinski et al. [68] aimed to evaluate the relationship between the N-terminal pro-brain natriuretic peptide (NTproBNP) which was considered as a cardiovascular risk factor for hypertension and the hemodynamic parameters measured by ICG. Hemodynamic parameters were recorded in patients with arterial hypertension in a supine position using the Niccomo device. They observed that NT-proBNP positively correlated with age $(p=0.00008), \operatorname{MBP}(p=0.0136)$, SI $(p=0.0065)$, CI $(p=0.0151)$, HI $(p<0.00001)$, whereas it negatively correlated with TFC $(p=0.0002)$. They found that the higher NT-proBNP was associated with higher age, higher MBP, higher HI and lower TFC; hence, age, MBP and HI were considered as predictor parameters of a high NT-proBNP. Therefore, they proved that the combination between the serum concentration of NT-proBNP and ICG measurements could provide more clinical information about hypertensive patients.

Krzesinski et al. [69], in another study, established a randomized, prospective and controlled trial in patients with hypertension. They tried to estimate the effectiveness of antihypertensive treatment based on hemodynamic parameters determined by ICG (Niccomo device) in therapy of hypertension. The patients enrolled in this study were divided in two groups: empiric group, where the treatment choice was based on clinical data; and hemodynamic group, where the treatment choice was based on hemodynamic parameters determined by ICG. The effects of each suggested treatment type were evaluated after $12 \mathrm{w}$ therapy. The authors signalled that they obtained positive effects of antihypertensive treatment in both groups. Precisely, they showed that all final blood pressure values were significantly lower in the hemodynamic group compared to the empiric group. Thus, they concluded that the antihypertensive treatment choice can be easily and effectively performed based on the hemodynamic parameters measured by ICG.

Xiajuan et al. [70] studied the relationship between Systolic Blood Pressure (SBP) and different hemodynamic parameters determined using ICG in elderly healthy subjects and elderly hypertensive patients. This study was performed in order to follow the hemodynamic changes occurred in normal aging subjects and in hypertensive aging patients. They showed lower values of CO, CI, SV and SI as well as higher values of SVR and SVRI in hypertensive elderly patients than in normal elderly subjects. In older subjects, the higher SBP was related to the increase of SVR values; with hypertension, these values were further increased. The obtained results revealed the importance of ICG technique in the management of hypertension.

\section{Pregnancy}

ICG technique has been proposed to evaluate the progression of pregnancy and also to investigate the hemodynamic parameter changes that occur in pregnant women. In this aspect, the use of ICG method is safe for both mother and child [71]. Therefore, numerous studies have been published regarding ICG in normal and high-risk pregnancy [72,73].

Tomsin et al. [74] tried to assess the relationship between maternal CO measured by ICG (NICCOMO device), birth weight percentile and cardiovascular physiology in women with preeclampsia. They found that $\mathrm{CO}$ measurements are significantly correlated with birth weight percentiles in low $\mathrm{CO}$ preeclampsia $(\mathrm{P}=0.002)$ than in high $\mathrm{CO}$ preeclampsia $(\mathrm{P}=0.044)$. However, they concluded that these results were associated with lower aortic flow indices and shorter venous pulse transit times in low than in high $\mathrm{CO}$ preeclampsia. A large prospective cohort trial was performed in an outpatient setting by Andreas et al. [75]. Indeed, the authors studied various cases of pregnancies by evaluating the occurred changes on hemodynamic parameters. The $\mathrm{CO}$ and other parameters (HR, SVR, SV, and BP) were recorded from the $11^{\text {th }}-13^{\text {th }} \mathrm{W}$ of gestation every $5^{\text {th }} \mathrm{W}$ as well as six weeks and six months postpartum using an ICG device. The measurements were carried out in two patient positions: in the supine and side positions. They observed an increase of $\mathrm{CO}$ values in the third trimester of pregnancy $(p=0.008)$ related to an increase of HR values $(p<0.001)$ and a decrease of SVR values $(p=0.009)$. Also, they noticed a significant increase of 
$\mathrm{CO}$ and HR values at early pregnancy in patients who had a complicated previous pregnancy or preeclampsia or a gestational hypertension. Moreover, they demonstrated that the $\mathrm{CO}$ variations can affect birth weight in healthy pregnancies. Furthermore, they proved that the body position could affect hemodynamic parameters towards the end of pregnancy.

Morris et al. [76] performed different ICG measurements at specific stages during gestation in order to normalize the ICGobtained values in healthy pregnant women. Indeed, antepartum measurements were performed at three gestational time periods: $20-27 \mathrm{w}, 28-33 \mathrm{w}$, and $34-40 \mathrm{w}$ of pregnancy, while postpartum measurements were carried out after the immediate puerperium at $6-24 \mathrm{~h}$ and $25-48 \mathrm{~h}$ after vaginal or cesarean delivery. In this study, CO, SVR, MAP and TFC hemodynamic parameters were computed by using Cardiodynamics BioZ-ICG-device. They clearly observed that the TFC and the SVR values for women in postpartum were significantly higher than for women in antepartum $(\mathrm{P}<0.05)$. They affirmed that the obtained normative values could be used to distinguish between healthy pregnant women and abnormal pregnant patients. Liu et al. [77] evaluated the ability of $\mathrm{CO}$ parameter which was determined continuously by EV (ICON device) to characterize the hemodynamic profile of patients undergoing spinal anesthesia for elective cesarean delivery. Different hemodynamic parameters were computed: HR, CO, SV, SVR and MAP. They noticed that hypotension arose in $71.1 \%$ of patients after spinal anesthesia; hence, an assigned dose of phenylephrine was administrated. In this study, the hemodynamic changes undertaken after the phenylephrine administration were studied. Regarding the $\mathrm{CO}$ monitoring, they remarked that a significant increase of $\mathrm{CO}$ occurred at 3-2 min before the administration of phenylephrine $(p<0.05)$, whereas a significant decrease of $\mathrm{CO}$ occurred after the administration of phenylephrine $(p<0.05)$. Consequently, they concluded that continuously $\mathrm{CO}$ monitoring using EV was able to detect hemodynamic changes prior the onset of hypotension in patients undergoing spinal anesthesia for elective cesarean delivery.

\section{Surgery}

ICG has been widely used for the assessment of hemodynamic parameters in patients under anesthesia, patients under mechanical ventilation as well as during different surgical operations at different patient positions [78-80]. Borodiciene et al. [81] compared hemodynamic changes assessed by ICG during anorectal surgery under low-dose spinal anesthesia in lithotomy and jackknife position. In this study, the CO, CI, SVR, and SI were determined at different times. They noticed statistically decrease of CO, CI and SI $(p<0.05)$ with an increase of SVR $(p<0.05)$ in jackknife position compared to the lithotomy position that represents an insignificant changes. Another study investigated the ability of ICG to evaluate the $\mathrm{CO}$ in patients undergoing open gastronomy surgery [82]. In this study, the $\mathrm{CO}$ values measured using ICG were compared with those measured using a FloTracTM/VigileoTM monitor that was used for measuring cardiac output by analyzing the arterial waveform. It has been demonstrated that ICG could provide useful and helpful information for evaluating the $\mathrm{CO}$ during abdominal surgery but it cannot perfectly replace the invasive $\mathrm{CO}$ monitor.

Smorenberg et al. [83] investigated the ability of ISTI parameter measured by ICG technique to predict fluid responsiveness in intensive care patients after coronary artery bypass surgery. A comparison was performed between the ISTI interval time and the hemodynamic parameters measured by thermodilution method which uses a pulmonary arterial catheter. They found that fluid responsiveness in patients after cardiac surgery can be accurately predicted and monitoring non-invasively using the ISTI parameter determined by ICG. The prediction of fluid responsiveness in spontaneously breathing patients under spinal anesthesia and during surgery has been studied by Guinot et al. [84]. In this study, the authors used the variation of $\mathrm{SV}$ " $\triangle \mathrm{SV}$ " derived from ICG in response to a fixed mini-fluid challenge. They concluded that a $\Delta \mathrm{SV}$ greater than $7 \%$ could accurately predict fluid responsiveness in spontaneously breathing patients under spinal anesthesia.

\section{Cardiovascular diseases}

ICG can be useful and reliable for diagnosing different cardiovascular diseases and for therapeutic decisions-making.

ICG has been used to assess hemodynamic changes in patients undergoing congestive heart disease repair [85]. Furthermore, this technique has been used by Ebrahim et al. [86] to evaluate hemodynamic changes in children with congenital heart disease. In this study, the SV values measured by ICG were compared with those measured by CMRI technique. The authors found that there was good agreement between ICG and CMRI for SV measurements in children with congenital heart defects.

Several studies have tried to investigate the ability of hemodynamic parameters determined by ICG to identify heart failure [87]. Sadauskas et al. [88] showed that an important number of ICG parameters might be useful for diagnosing and monitoring heart failure. Other studies evaluated the usefulness of ICG in the prediction of the effects of heart failure treatment [89-92].

Valvular heart diseases have been also diagnosed and quantified by using ICG. Chabchoub et al. [93] confirmed the accuracy of ICG in the diagnosis of mitral insufficiency. The authors proposed a new diagnostic parameter which was determined from the ICG waveform. This parameter could accurately distinguish healthy subjects from patients with mitral insufficiency. Daralammouri et al. [94] established a hybrid approach by coupling ICG with Transthoracic Echocardiography (TTE) for quantifying aortic valve stenosis. The aortic valve area values determined by the hybrid method were compared with those measured by cardiac catheterization. They found that the hybrid approach was significantly correlated to the catheterization method $(\mathrm{p}<0.01)$; thus the hybrid approach could accurately quantify the aortic valve stenosis severity. 
Another study shows that the ICG method could be used in myocardial infarction. Chen at al. [95] used the ICG-derived parameters to evaluate changes of cardiac functions in patients with acute myocardial infarction. Twelve hemodynamic parameters have been measured by ICG and by echocardiography. They noticed that there were statistical correlations between ICG and echocardiography for all determined parameters except the PEP.

\section{Other clinical applications}

ICG can be successfully applied in several other clinical applications. It has been used for atrioventricular-delay optimization as well as for evaluating the optimal settings of the pacemakers [96-98] and during hemodialysis [99,100]. Furthermore, ICG has been used to investigate the effects of different postural changes on various hemodynamic parameters in infants and adults [101-104].

\section{Major Limitations of Impedance Cardiography}

Despite the simplicity and the various advantages of ICG technique, its use can be associated with some limitations. Therefore, inaccurate and unreliable results can be occurred in the following situations [9,105-107].

- Motion artifacts and during exercise.

- Incorrect electrode placement.

- Atrial fibrillation.

- Arrhythmia and tachycardia, which can contribute to incorrect determination of hemodynamic parameters.

- Severe valvular heart diseases, especially severe aortic insufficiency.

- ICG is not suitable for subjects of very small or very large size and weight.

- ICG is not recommended for patients with pacemakers.

\section{Conclusion}

This paper illustrates an overview of impedance cardiography technique. The important number of researches in this area proves the importance and the usefulness of this technique in different applications. Despite the limitations and some negative experiences obtained with ICG, many researchers insisted that there are many hopes for the clinical utility and the reliability of this important method. Therefore, ICG has been considered to be a very promising approach for the determination and the real-time monitoring of $\mathrm{SV}, \mathrm{CO}$ and different other hemodynamic parameters. In this respect, several ICG devices have been developed and commercialized such as Niccomo monitor, Cardio Screen 1000 monitor, BioZ, Aesculon monitor, etc. The performance of each of this monitor has been ameliorated in order to improve the ICG signal quality, by using different signal processing algorithms and different electrode configurations.

\section{References}

1. Lee AJ, Cohn JH, Ranasinghe JS. Cardiac output assessed by invasive and minimally invasive techniques. Anesthesiol Res Pract 2011.

2. Salmasi AM. Cardiac output in coronary artery disease. Card Output Reg Flow Health Dis 1993; 127-135.

3. Karamanoglu M, Bennett T, Stahlberg M, Splett V, Kjellström B, Linde C, Braunschweig F. Estimation of cardiac output in patients with congestive heart failure by analysis of right ventricular pressure waveforms. Biomed Eng Online 2011; 10: 36.

4. Gilbert M. Cardiac output measurement. Anaesth Intens Care Med 2013; 14: 63-67.

5. Mehta Y, Arora D. Newer methods of cardiac output monitoring. World J Cardiol 2014; 6: 1022-1029.

6. Thiele RH, Bartels K, Gan TJ. Cardiac output monitoring: a contemporary assessment and review. Crit Care Med 2015; 43: 177-185.

7. Parry MJ, McFetridge-Durdle J. Ambulatory impedance cardiography: a systematic review. Nurs Res 2006; 55: 283-291.

8. Cybulski G, Strasz A, Niewiadomski WGA, Siorowska A. Impedance cardiography: recent advancements. Cardiol J 2012; 19: 550-556.

9. Sodolski T, Kutarski A. Impedance cardiography: A valuable method of evaluating haemodynamic parameters. Cardiol J 2007; 14: 115-126.

10. Patterson RP. Fundamentals of impedance cardiography. IEEE Eng Med Biol Mag 1989; 8: 35-38.

11. Woltjer HH, Bogaard HJ, de Vries PM. The technique of impedance cardiography. Eur Heart J 1997; 18: 1396-1403.

12. Kubicek WG, Patterson RP, Witsoe DA. Impedance cardiography as a noninvasive method of monitoring cardiac function and other parameters of the cardiovascular system. Ann NY Acad Sci 1970; 170: 724-732.

13. Lababid Z, Ehmke DA, Durnin RE, Leaverton PE, Lauer RM. The first derivative thoracic impedance cardiogram. Circulation 1970; 41: 651-658.

14. Penney BC, Patwardhan NA, Wheeler HB. Simplified electrode array for impedance cardiography. Med Biol Eng Comput 1985; 23: 1-7.

15. Ben Salah R, Marrakchi A, Ellouze N. Cardiac diseases quantification of by temporal and cepstral analysis of plethysmographic signal. J Islam Acad Sci 1989; 2: 204-211.

16. Meijer JH, Elbertse E, Boesveldt S, Berendse HW, Verdaasdonk RM. Using the Initial Systolic Time Interval to assess cardiac autonomic nervous function in Parkinsons disease. J Electr Bioimp 2011; 2: 98-101.

17. Meijer JH, Boesveldt S, Elbertse E, Berendse HW. Method to measure autonomic control of cardiac function using time interval parameters from impedance cardiography. Physiol Meas 2008; 29: 383-391. 
18. Takada K, Fujinami T, Senda K, Nakayama K, Nakano S. Clinical study of A waves (atrial waves) in impedance cardiograms. Am Heart J 1977; 94: 710-717.

19. Cybulski G. Ambulatory impedance cardiography. Lecture Notes Electric Eng 2011; 76.

20. Ono T, Miyamura M, Yasuda Y, Ito T, Saito T, Ishiguro T, Yoshizawa M, Yambe T. Beat-to-beat evaluation of systolic time intervals during bicycle exercise using impedance cardiography. Tohoku J Exp Med 2004; 203: 17-29.

21. Lozano DL, Norman G, Knox D, Wood BL, Miller BD, Emery CF, Berntson GG. Where to $B$ in $\mathrm{dZ} / \mathrm{dt}$. Psychophysiology 2007; 44: 113-119.

22. Sherwood A, Allen MT, Fahrenberg J, Kelsey RM, Lovallo WR, Van Doornen LJ. Methodological guidelines for impedance cardiography. Psychophysiology 1990; 27: $1-23$.

23. DeMarzo AP, Lang RM. A new algorithm for improved detection of aortic valve opening by impedance cardiography. Comp Cardiol 1996; 373-376.

24. Goldstein DS, Cannon RO, Zimlichman R, Keiser HR. Clinical evaluation of impedance cardiography. CIin Physiol 1986; 6: 235-251.

25. Visser KR, Mook GA, van der Wall E, Zijlstra WG. Theory of the determination of systolic time intervals by impedance cardiography. Biol Psychol 1993; 36: 43-50.

26. Albert NM. Bioimpedance cardiography measurements of cardiac output and other cardiovascular parameters. Crit Care Nurs Clin North Am 2006; 18: 195-202.

27. Van Eijnatten MAJM, Van Rijssel MJ, Peters RJA , Verdaasdonk RM, Meijer JH. Comparison of cardiac time intervals between echocardiography and impedance cardiography at various heart rates. J Electr Bioimp 2014; 5: 2-8.

28. Van Lien R, Schutte NM, Meijer JH, de Geus EJC. Estimated preejection period (PEP) based on the detection of the R-wave and $\mathrm{dZ} / \mathrm{dt}$-min peaks does not adequately reflect the actual PEP across a wide range of laboratory and ambulatory conditions. Int J Psychophysiol 2013; 87: 60-69.

29. Meijer JH, Smorenberg A, Lust EJ, Verdaasdonk RM, Johan Groeneveld AB. Assessing cardiac preload by the Initial Systolic Time Interval obtained from impedance cardiography. J Electr Bioimp 2010; 1: 80-83.

30. Stepanov R, Podtaev S, Dumler A, Chugainov S. Assessment of cardiac time intervals by wavelet transform of the impedance cardiogram. Technol Health Care 2016; 24: 803-809.

31. Bagal UR, Pandey PC, Naidu SMM, Hardas S. Detection of opening and closing of the aortic valve using impedance cardiography and its validation by echocardiography. Biomed Phys Eng Express 2017.

32. Seery MD, Kondrak CL, Streamer L, Saltsman T, Lamarche VM. Preejection period can be calculated using $\mathrm{R}$ peak instead of Q. Psychophysiology 2016; 53: 1232-1240.
33. Arbol JR, Perakakis P, Garrido A, Mata JL, FernándezSantaella MC, Vila J. Mathematical detection of aortic valve opening (B point) in impedance cardiography: A comparison of three popular algorithms. Psychophysiology 2017; 54: 350-357.

34. Van Lien R, Schutte NM, Meijer JH, de Geus EJ. Estimated preejection period (PEP) based on the detection of the R-wave and dZ/dt-min peaks does not adequately reflect the actual PEP across a wide range of laboratory and ambulatory conditions. Int J Psychophysiol 2013; 87: 60-69.

35. Ermishkin VV, Kolesnikov VA, Lukoshkova EV. Agedependent and pathologic changes in ICG waveforms resulting from superposition of pre-ejection and ejection waves. Physiol Meas 2014; 35: 943-963.

36. Fellahi JL, Fischer MO. Electrical bioimpedance cardiography: an old technology with new hopes for the future. J Cardiothorac Vasc Anesth 2014; 28: 755-760.

37. Bernstein DP. Impedance cardiography: pulsatile blood flow and the biophysical and electrodynamic basis for the stroke volume equations. J Electr Bioimp 2010; 1: 2-17.

38. Sramek BB, Rose DM, Miyamoto A. Stroke volume equation with a linear base impedance model and its accuracy, as compared to thermodilution and magnetic flowmeter techniques in humans and animals. Proceedings of Sixth International Conference on Electrical Bioimpedance, Zadar, Yugoslavia 1983; 38-41.

39. Bernstein DP. A new stroke volume equation for thoracic electrical bioimpedance: theory and rationale. Crit Care Med 1986; 14: 904-909.

40. Bernstein DP, Lemmens HJ. Stroke volume equation for impedance cardiography. Med Biol Eng Comput 2005; 43: 443-450.

41. Cheung H, Dong Q, Dong R, Yu B. Correlation of cardiac output measured by non-invasive continuous cardiac output monitoring (NICOM) and thermodilution in patients undergoing off-pump coronary artery bypass surgery. J Anesth 2015; 29: 416-420.

42. Conway DH, Hussain OA, Gall I. A comparison of noninvasive bioreactance with oesophageal Doppler estimation of stroke volume during open abdominal surgery: an observational study. Eur J Anaesthesiol 2013; 30: 501-508.

43. Huang L, Critchley LA, Zhang J. Major upper abdominal surgery alters the calibration of bioreactance cardiac output readings, the NICOM, when comparisons are made against suprasternal and esophageal doppler intraoperatively. Anesth Analg 2015; 121: 936-945.

44. Kober D, Trepte C, Petzoldt M, Nitzschke R, Herich L, Reuter DA, Haas S. Cardiac index assessment using bioreactance in patients undergoing cytoreductive surgery in ovarian carcinoma. J Clin Monit Comput 2013; 27: 621-627.

45. Noda K, Endo H, Kadosaka T, Nakata T, Watanabe T, Terui Y, Kajitani S, Monnma Y, Sato K, Kanazawa M, Nakajima S, Kondo M, Takahashi T, Nakamura A, Nozaki 
E. Comparison of the measured pre-ejection periods and left ventricular ejection times between echocardiography and impedance cardiography for optimizing cardiac resynchronization therapy. J Arrhythm 2017; 33: 130-133.

46. Germain MJ, Joubert J, OGrady D, Nathanson BH, Chait Y, Levin NW. Comparison of stroke volume measurements during hemodialysis using bioimpedance cardiography and echocardiography. Hemodial Int 2017.

47. McIntyre JP, Ellyett KM, Mitchell EA, Quill GM, Thompson JM, Stewart AW, Doughty RN, Stone PR, Maternal Sleep in Pregnancy Study Group. Validation of thoracic impedance cardiography by echocardiography in healthy late pregnancy. BMC Pregnancy Childbirth 2015; 15: 70 .

48. Burlingame J, Ohana P, Aaronoff M, Seto T. Noninvasive cardiac monitoring in pregnancy: impedance cardiography versus echocardiography. J Perinatol 2013; 1-6.

49. Kaszuba E, Scheel S, Odeberg H, Halling A. Comparing impedance cardiography and echocardiography in the assessment of reduced left ventricular systolic function. BMC Research Notes 2013; 6: 114.

50. Faini A, Omboni S, Tifrea $\mathrm{M}$, Bubenek S, Lazar O, Parati G. Cardiac index assessment: Validation of a new noninvasive very low current thoracic bioimpedance device by thermodilution. Blood Pressure 2013; 1-7.

51. Kupersztych-Hagege E, Teboul JL, Artigas A, Talbot A, Sabatier C, Richard C, Monnet X. Bioreactance is not reliable for estimating cardiac output and the effects of passive leg raising in critically ill patients. $\mathrm{Br} \mathrm{J}$ Anaesth 2013; 111: 961-966.

52. Lorne E, Mahjoub Y, Diouf M, Sleghem J, Buchalet C, Guinot PG, Petiot S, Kessavane A, DehedinB, Dupont H. Accuracy of impedance cardiography for evaluating trends in cardiac output: a comparison with oesophageal Doppler. Br J Anaesth 2014; 113: 596-602.

53. Borzage M, Heidari K, Chavez T, Seri I, Wood JC, Bluml S. Measuring stroke volume: impedance cardiography vs. phase-contrast magnetic resonance imaging. Am J Crit Care 2017; 26: 408-415.

54. Trinkmann F, Berger M, Doesch C, Papavassiliu T, Schoenberg SO, Borggrefe M, Kaden JJ, Saur J. Comparison of electrical velocimetry and cardiac magnetic resonance imaging for the non-invasive determination of cardiac output. J Clin Monit Comput 2016; 30: 399-408.

55. Blohm ME, Obrecht D, Hartwich J, Mueller GC, Kersten JF, Weil J, Singer D. Impedance cardiography (electrical velocimetry) and transthoracic echocardiography for noninvasive cardiac output monitoring in pediatric intensive care patients: a prospective single-center observational study. Crit Care 2014; 18: 603.

56. Grollmuss O, Gonzalez P. Non-invasive cardiac output measurement in low and very low birth weight infants: a method comparison. Front Pediatr 2014; 2: 16.

57. Sasaki K, Mutoh T, Mutoh T, Kawashima R, Tsubone H. Electrical velocimetry for noninvasive cardiac output and stroke volume variation measurements in dogs undergoing cardiovascular surgery. Vet Anaesth Analg 2017; 44: 7-16.

58. ODonnell CJ, Elosua R. Cardiovascular risk factors. Insights from Framingham Heart Study. Rev Esp Cardiol 2008; 61: 299-310.

59. Weycker D, Nichols GA, OKeeffe-Rosetti M, Edelsberg J, Khan ZM, Kaura S, Oster G. Risk-factor clustering and cardiovascular disease risk in hypertensive patients. Am J Hypertens 2007; 20: 599-607.

60. Aparicio LS, Alfie J, Barochiner J, Cuffaro PE, Giunta DH, Elizondo CM, Tortella JJ, Morales MS, Rada MA, Waisman GD. Comparison of atenolol versus bisoprolol with noninvasive hemodynamic and pulse wave assessment. J Am Soc Hypertens 2015; 9: 390-396.

61. DeMarzo AP. Using impedance cardiography to detect asymptomatic cardiovascular disease in prehypertensive adults with risk factors. High Blood Press Cardiovasc Prev 2013; 20: 61-67.

62. Krzesinski P, Uzieblo-Zyczkowska B, Gielerak G, Stanczyk A, Kurpaska M, Piotrowicz K. Global longitudinal two-dimensional systolic strain is associated with hemodynamic alterations in arterial hypertension. J Am Soc Hypertens 2015; 9: 680-689.

63. Morris R, Sunesara I, Darby M, Novotny S, Kiprono L, Bautista L, Sawardecker S, Bofill J, Anderson B, Martin JN. Impedance cardiography assessed treatment of acute severe pregnancy hypertension: a randomized trial. J Matern Fetal Neonatal Med 2016; 29: 171-176.

64. Rada MA, Cuffaro PE, Galarza CR, Barochiner J, Alfie J, Posadas Martinez ML, Giunta DH, Morales MS, Aparicio LS, Waisman GD. Predictive value of non-invasive hemodynamic measurement by means of impedance cardiography in hypertensive subjects older than 50 years of age. Clin Exp Hypertens 2014; 36: 280-284.

65. Cave BE, Hough AR. Impedance cardiography to guide antihypertensive treatment in a patient with difficult-totreat hypertension. Ann Clin Exp Hypertension 2017; 5: 1050.

66. Aoka Y, Hagiwara N, Kasanuki H. Heterogeneity of hemodynamic parameters in untreated primary hypertension, and individualization of antihypertensive therapy based on noninvasive hemodynamic measurements. Clin Exp Hypertens 2013; 35: 61-66.

67. Barochiner J, Aparicio LS, Alfie J, Rada MA, Morales MS, Galarza CR, Cuffaro PE, Marín MJ, Martínez R, Waisman GD. Hemodynamic characterization of hypertensive patients with an exaggerated orthostatic blood pressure variation. Clin Exp Hypertens 2017; 12: $1-5$.

68. Krzesinski P, Gielerak G, Stanczyk A, Piotrowicz K, Piechota W, Skrobowski A. Association of N-terminal pro-brain natriuretic peptide and hemodynamic parameters measured by impedance cardiography in patients with essential hypertension. Clin Exp Hypertens 2015; 37: 148-154. 
69. Krzesinski P, Gielerak GG, Kowal JJ. A patient-tailored treatment of hypertension with use of impedance cardiography: a randomized, prospective and controlled trial. Med Sci Monit 2013; 19: 242-250.

70. Zhao X, Ding D, Huang Y, Hong Z. Impedance cardiographic hemodynamic variables and hypertension in elderly Han residents. Ups J Med Sci 2013; 118: 80-86.

71. Staelens A, Tomsin K, Grieten L, Oben J, Mesens T, Spaanderman M, Jacquemyn Y, Gyselaers W. Noninvasive assessment of gestational hemodynamics: benefits and limitations of impedance cardiography versus other techniques. Expert Rev Med Devices 2013; 765-779.

72. Oben J, Tomsin K, Mesens T, Staelens A, Molenberghs G, Gyselaers W. Maternal cardiovascular profiling in the first trimester of pregnancies complicated with gestationinduced hypertension or fetal growth retardation: a pilot study. J Matern Fetal Neonatal Med 2014; 27: 1646-1651.

73. Ram M, Lavie A, Lev S, Blecher Y, Amikam U, Shulman Y, Avnon T, Weiner E, Many A. Casting doubt on the value of assessing the cardiac index in pregnancy. $\mathrm{J}$ Matern Fetal Neonatal Med 2017; 13: 1-5.

74. Tomsin K, Mesens T, Molenberghs G, Peeters L, Gyselaers W. Characteristics of heart, arteries, and veins in low and high cardiac output preeclampsia. Eur J Obstet Gynecol Reprod Biol 2013; 169: 218-222.

75. Andreas M, Kuessel L, Kastl SP, Wirth S, Gruber K, Rhomberg F, Gomari-Grisar FA, Franz M, Zeisler H, Gottsauner-Wolf M. Bioimpedance cardiography in pregnancy: A longitudinal cohort study on hemodynamic pattern and outcome. BMC Pregnancy Childbirth 2016; 16: 128.

76. Morris R, Sunesara I, Rush L, Anderson B, Blake PG, Darby M, Sawardecker S, Novotny S, Bofill JA, Martin JN Jr. Maternal hemodynamics by thoracic impedance cardiography for normal pregnancy and the postpartum period. Obstet Gynecol 2014; 123: 318-324.

77. Liu Y, Pian-Smith MC, Leffert LR, Minehart RD, Torri A, Coté C, Kacmarek RM, Jiang Y. Continuous measurement of cardiac output with the electrical velocimetry method in patients under spinal anesthesia for cesarean delivery. J Clin Monit Comput 2015; 29: 627-634.

78. Han S, Lee JH, Kim G, Ko JS, Choi SJ, Kwon JH, Heo BY, Gwak MS. Bioreactance is not interchangeable with thermodilution for measuring cardiac output during adult liver transplantation. PLoS One 2015; 10: 0127981.

79. Labib HAA, Hussien RM, Salem YA. Monitoring the correlation between passive leg-raising maneuver and fluid challenge in pediatric cardiac surgery patients using impedance cardiography. Egypt J Cardiothorac Anesth 2016; 10: 17-22.

80. Lee JY, Kim JY, Choi CH, Kim HS, Lee KC, Kwak HJ. The ability of stroke volume variation measured by a noninvasive cardiac output monitor to predict fluid responsiveness in mechanically ventilated children. Pediatr Cardiol 2014; 35: 289-294.
81. Borodiciene J, Gudaityte J, Macas A. Lithotomy versus jack-knife position on haemodynamic parameters assessed by impedance cardiography during anorectal surgery under low dose spinal anaesthesia: a randomized controlled trial. BMC Anesthesiol 2015; 15: 74.

82. Kim JY, Kim BR, Lee KH, Kim KW, Kim JH, Lee SI, Kim KT, Choe WJ, Park JS, Kim JW. Comparison of cardiac output derived from FloTrac ${ }^{\mathrm{TM}} / \mathrm{Vigileo}^{\mathrm{TM}}$ and impedance cardiography during major abdominal surgery. J Int Med Res 2013; 41: 1342-1349.

83. Smorenberg A, Lust EJ, Beishuizen A, Meijer JH, Verdaasdonk RM, Groeneveld AB. Systolic time intervals vs. invasive predictors of fluid responsiveness after coronary artery bypass surgery. Eur J Cardiothorac Surg 2013; 44: 891-897.

84. Guinot PG, Bernard E, Defrancq F, Petiot S, Majoub Y, Dupont H, Lorne E. Mini-fluid challenge predicts fluid responsiveness during spontaneous breathing under spinal anaesthesia: an observational study. Eur J Anaesthesiol 2015; 32: 645-649.

85. Legendre A, Bonnet D, Bosquet L. Reliability of peak exercise stroke volume assessment by impedance cardiography in patients with residual right outflow tract lesions after congenital heart disease repair. Pediatr Cardiol 2017.

86. Ebrahim M, Hegde S, Printz B, Abcede M, Proudfoot JA, Davis C. Evaluation of impedance cardiography for measurement of stroke volume in congenital heart disease. Pediatr Cardiol 2016; 37: 1453-1457.

87. Facchini C, Malfatto G, Giglio A, Facchini M, Parati G, Branzi G. Lung ultrasound and transthoracic impedance for noninvasive evaluation of pulmonary congestion in heart failure. J Cardiovasc Med 2016; 17: 510-517.

88. Sadauskas S, Naudžiunas A, Unikauskas A, Mašanauskiene E, Bakšyte G, Macas A. Applicability of impedance cardiography during heart failure flare-ups. Med Sci Monit 2016; 22: 3614-3622.

89. Gielerak G, Krzesinski P, Piotrowicz E, Piotrowicz R. The usefulness of impedance cardiography for predicting beneficial effects of cardiac rehabilitation in patients with heart failure. Biomed Res Int 2013; 2013: 595369.

90. Falls R, Seman M, Braat S, Sortino J, Allen JD, Neil CJ. Inorganic nitrate as a treatment for acute heart failure: a protocol for a single center, randomized, double-blind, placebo-controlled pilot and feasibility study. J Transl Med 2017; 15: 172.

91. Stirrat CG, Venkatasubramanian S, Pawade T, Mitchell AJ, Shah AS, Lang NN, Newby DE. Cardiovascular effects of urocortin 2 and urocortin 3 in patients with chronic heart failure. Br J Clin Pharmacol 2016; 82: 974-982.

92. Mumma BE, Dhingra KR, Kurlinkus C, Diercks DB. Hemodynamic effects of nitroglycerin ointment in emergency department patients. J Emerg Med 2014; 47: 192-197. 
93. Chabchoub S, Mansouri S, Ben Salah R. Diagnosis of mitral insufficiency using impedance cardiography technique ICG. J Electr Bioimp 2016; 7: 28-34.

94. Daralammouri Y, Ayoub K, Badrieh N, Lauer B. A hybrid approach for quantifying aortic valve stenosis using impedance cardiography and echocardiography. BMC Cardiovasc Disord 2016; 16: 19.

95. Chen SJ, Gong Z, Duan QL. Evaluation of heart function with impedance cardiography in acute myocardial infarction patients. Int J Clin Exp Med 2014; 7: 719-727.

96. Klimczak A, Budzikowski AS, Rosiak M, Zielinska M, Urbanek B, Bartczak K, Chudzik M, Wranicz JK. Influence of atrioventricular optimization on hemodynamic parameters and quality of life in patients with dual chamber pacemaker with ventricular lead in right ventricular outflow tract. Ann Noninvasive Electrocardiol 2014; 19: 471-476.

97. Urbanek B, Chudzik M, Klimczak A, Rosiak M, Lewek J, Wranicz JK. Whether noninvasive optimization of AV and VV delays improves the response to cardiac resynchronization therapy. Cardiol J 2013; 20: 411-417.

98. Krychtiuk KA, Nürnberg M, Volker R, Pachinger L, Jarai R, Freynhofer MK, Wojta J, Huber K, Weiss TW. Effects of AV-delay optimization on hemodynamic parameters in patients with VDD pacemakers. Wien Klin Wochenschr 2014; 126: 270-277.

99. Germain MJ, Joubert J, OGrady D, Nathanson BH, Chait Y, Levin NW. Comparison of stroke volume measurements during hemodialysis using bioimpedance cardiography and echocardiography. Hemodial Int 2017.

100. Yoshihara F, Kishida M, Ogawa K, Nishigaki T, Nakasaki $\mathrm{H}$, Ishizuka A, Koezuka $\mathrm{R}$, Matsuo $\mathrm{M}$, Hayashi $\mathrm{T}$, Nakamura S. High stroke volume variation is an independent predictor for decreased blood pressure during hemodialysis. Ther Apher Dial 2017; 21: 166-172.

101. Kubota S, Endo Y, Kubota M, Ishizuka Y, Furudate T. Effects of trunk posture in Fowlers position on hemodynamics. Autonom Neurosci Basic Clin 2015; 189: 56-59.

102. Wu TW, Lien RI, Seri I, Noori S. Changes in cardiac output and cerebral oxygenation during prone and supine sleep positioning in healthy term infants. Arch Dis Child Fetal Neonatal Ed 2017; 102: 483-489.

103. Ma M, Noori S, Maarek JM, Holschneider DP, Rubinstein EH, Seri I. Prone positioning decreases cardiac output and increases systemic vascular resistance in neonates. J Perinatol 2015; 35: 424-427.

104. Paviotti G, Todero S, Demarini S. Cardiac output decreases and systemic vascular resistance increases in newborns placed in the left-lateral position. J Perinatol 2017; 37: 563-565.

105. Summers RL, Shoemaker WC, Peacock WF, Ander DS, Coleman TG. Bench to bedside: electrophysiologic and clinical principles of noninvasive hemodynamic monitoring using impedance cardiography. Acad Emerg Med 2003; 10: 669-680.

106. Parmar CV, Prajapati DL, Chavda VV, Gokhale PA, Mehta HB, Shah CJ. A study of cardiac parameters using impedance plethysmography (IPG) in healthy volunteers. J Phys Pharm Adv 2012; 2: 365-379.

107. Wang DJ, Gottlieb SS. Impedance cardiography: more questions than answers. Curr Heart Fail Rep 2006; 3: 107-113.

\section{*Correspondence to}

Sofienne Mansouri

Department of Medical Equipment Technology

College of Applied Medical Sciences

Prince Sattam Bin Abdulaziz University

Kingdome of Saudi Arabia 